\title{
On Intuitionistic sgp-closed sets in Intuitionistic Topological Space
}

\author{
P. Agrawal $^{*}$ and J.K Maitra ${ }^{2}$ \\ ${ }^{1}$ Department of Mathematics and Computer Science, Rani Durgawati University, Jabalpur (M.P.) India \\ ${ }^{2}$ Department of Mathematics and Computer Science, Rani Durgawati University, Jabalpur (M.P.) India
}

\section{Available online at: www.isroset.org}

Accepted 10/Aug/2018, Online 30/Aug/2018

\begin{abstract}
In 2007, Navalagi and Bhat introduced and study a new class of sets, namely, sgp-closed sets in Topological Spaces. He observed that this class is properly placed between the class of closed sets and generalized preclosed sets. In this paper we have introduced intuitionistic sgp-closed sets and intuitionistic sgp-open sets in intuitionistic toplogical spaces and obtained its significant properties. We have constructed some examples which are quite useful in theory of intuitionistic sgp-closed and intuitionistic sgp-open sets.
\end{abstract}

Keywords: Intuitionistic sgp closed set, Intuitionistic sgp-open set.

\section{INTRODUCTION}

The notation of intuitionistic set was introduced by Coker [4] in 1996, and also he [5] has introduced the concept of intuitionistic topological spaces. Bajpai and Thakur [11] have introduced the concept of intuitionistic fuzzy sgpclosed sets in intuitionistic fuzzy topological spaces in 2017. In this paper we have obtained some significant properties of intuitionistic sgp-closed sets and intuitionistic sgp-open sets in intuitionistic toplogical spaces.

\section{PRELIMINARIES}

In this section we have studied set theoretical results of intuitionistic sets. Futher we have studied some generalized forms of intuitionistic open and intuitionistic closed set in intuitionistic topological space.

Definition 2.1 [4] Let $X$ is a non empty set. An intuitionistic set (IS for short) $A$ is an object having the form $A=\angle X, A_{1}$ ,$A_{2}>$, where $A_{1}$ and $A_{2}$ are subsets of $X$ satisfying $A_{1} \cap A_{2}$ $=\Phi$. The set $A_{1}$ is called the set of members of $A$, while $A_{2}$ is called the set of nonmembers of A.

Definition 2.2 [4] Let $X$ be a non empty set and let A, B are intuitionistic sets in $\mathrm{X}$ of the form $\mathrm{A}=\left\langle\mathrm{X}, \mathrm{A}_{1}, \mathrm{~A}_{2}\right\rangle, \mathrm{B}=<$ $\mathrm{X}, \mathrm{B}_{1}, \mathrm{~B}_{2}>$ respectively. Then

1. $\mathrm{A} \subseteq \mathrm{B}$ iff $\mathrm{A}_{1} \subseteq \mathrm{B}_{1}$ and $\mathrm{B}_{2} \subseteq \mathrm{A}_{2}$;

2. $\mathrm{A}=\mathrm{B}$ iff $\mathrm{A} \subseteq \mathrm{B}$ and $\mathrm{B} \subseteq \mathrm{A}$;

3. $\mathrm{A}^{\mathrm{c}}=\left\langle\mathrm{X}, \mathrm{A}_{2}, \mathrm{~A}_{1}>\right.$;

4. $\Phi \sim=<\mathrm{X}, \Phi, \mathrm{X}>, \mathrm{X} \sim=<\mathrm{X}, \mathrm{X}, \Phi>$;
5. $A \cup B=<X, A_{1} \cup B_{1}, A_{2} \cap B_{2}>$;

6. $\mathrm{A} \cap \mathrm{B}=<\mathrm{X}, \mathrm{A}_{1} \cap \mathrm{B}_{1}, \mathrm{~A}_{2} \cup \mathrm{B}_{2}>$;

Further if $\left\{A_{i}: i \in J\right\}$ is an arbitrary family of intuitionistic sets in $X$, where $A_{i}=\left\langle X, A_{i}{ }^{(1)}, A_{i}{ }^{(2)}\right\rangle$. Then

7. $\cap A_{i}=<X, \cap A_{i}, \cup A_{i}>$;

8. $\cup A_{i}=<X, \cup A_{i}, \cap A_{i}>$;

Definition 2.3 [5] An intuitionistic topology (for short IT) on a non empty set $\mathrm{X}$ is a family of ISs in $\mathrm{X}$ satisfying the following axioms.

1. $\Phi \sim, \mathrm{X} \sim \tau$.

2. $G_{1} \cap G_{2} \in \tau$ for any $G_{1}, G_{2} \in \tau$.

3. $\cup G_{i} \in \tau$ for any arbitrary family $\left\{G_{i}: i \in J\right\} \subseteq \tau$. In this case the pair $(X, \tau)$ is called an intuitionistic topological space(for short ITS) and any intuitionistic set in $\tau$ is known as an intuitionistic open set (for short IOS) in X. The complement $A^{c}$ of an Intuitionistic open set $A$ is known as an intuitionistic closed set (for short ICS) in X.

Definition 2.4 [4] Let $X$ be a non empty set and $p \in X$. Then the IS $\mathrm{P}$ defined by $\mathrm{P}=\left\langle\mathrm{X},\{\mathrm{p}\},\{\mathrm{p}\}^{\mathrm{c}}\right\rangle$ is called an intuitionistic point (IP for short) in $X$. The intuitionistic point $P$ is said to be contained in $A=<X, A_{1}, A_{2}>$ (i.e $p \in A$ ) if and only if $p \in A_{1}$.

Definition 2.5 [5] Let $(X, \tau)$ be an Intuitionistic topological spaces and $\mathrm{A} \subseteq \mathrm{X}$. Then intuitionistic closure of $\mathrm{A}$ is defined as the intersection of all intuitionistic closed sets in $\mathrm{X}$ containing A. The intuitionistic closure of $\mathrm{A}$ is denoted by 
$\operatorname{Icl}(\mathrm{A})$.

Definition 2.6 [5] Let (X, $\tau)$ be an Intuitionistic topological spaces and $\mathrm{A} \subseteq \mathrm{X}$. Then intuitionistic interior of $\mathrm{A}$ is defined as the union of all intuitionistic open sets in $X$ contained in A. The intuitionistic interior of $\mathrm{A}$ is denoted by $\operatorname{Iint}(\mathrm{A})$.

Definition 2.7 [6] Let $(X, \tau)$ be an ITS. Then intuitionistic set $A$ of $X$ is said to be

(1) Intuitionistic semiclosed (for short Is-closed) set if $\mathrm{A} \supseteq \operatorname{Iint}(\operatorname{Icl}(\mathrm{A}))$.

(2) Intuitionistic preclosed (for short Ip-closed) set if A $\supseteq \operatorname{Icl}(\operatorname{Iint}(\mathrm{A}))$.

(3) Intuitionistic $\alpha$-closed (for short I $\alpha$-closed) set if A $\supseteq \operatorname{Icl}(\operatorname{Iint}(\operatorname{Icl}(\mathrm{A})))$.

(4) Intuitionistic $\beta$-closed [1] (for short I $\beta$-closed) set if $\mathrm{A} \supseteq \operatorname{Iint}(\operatorname{Icl}(\operatorname{Iint}(\mathrm{A})))$.

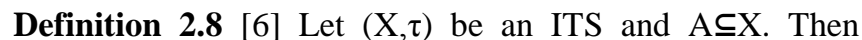
intuitionistic pre-closure of $\mathrm{A}$ is defined as the intersection of all intuitionistic pre-closed sets in $\mathrm{X}$ containing A. The intuitionistic pre-closure of A is denoted by $\operatorname{Ipcl}(\mathrm{A})$.

Theorem 2.1 [8] Let $(\mathrm{X}, \tau)$ be an ITS and $\left\{\mathrm{A}_{\alpha}: \alpha \in \mathrm{I}\right\}$ be a family of intuitionistic semiopen sets in $X$. Then $\cup_{\alpha \in I} A_{\alpha}$ is also an Intuitionistic semiopen set.

Lemma 2.1 [8] Let $(X, \tau)$ be an ITS. If $A$ and $B$ be are two intuitionistic semiopen sets in $\mathrm{X}$, then $\mathrm{A} \cap \mathrm{B}$ is not necessarily to be an intuitionistic semiopen set.

Theorem 2.2 [9] Let $(\mathrm{X}, \tau)$ be an ITS and $\left\{\mathrm{A}_{\alpha}: \alpha \in \mathrm{I}\right\}$ be a family of intuitionistic preopen sets in $X$. Then $U_{\alpha \in I} A_{\alpha}$ is also an Intuitionistic preopen set.

Lemma 2.2 [9] Let $(\mathrm{X}, \tau)$ be an ITS. If $\mathrm{A}$ and $\mathrm{B}$ be are two intuitionistic preopen sets in $\mathrm{X}$, then $\mathrm{A} \cap \mathrm{B}$ is not necessarily to be an intuitionistic preopen set. But if one of the set is an IO set. Then $\mathrm{A} \cap \mathrm{B}$ is an intuitionistic preopen set.

Theorem 2.3 [10] Let $(X, \tau)$ be an ITS and $\left\{A_{\alpha}: \alpha \in I\right\}$ be a family of intuitionistic $\alpha$-open sets in $\mathrm{X}$. Then $\mathrm{U}_{\alpha \in \mathrm{I}} \mathrm{A}_{\alpha}$ is also an Intuitionistic $\alpha-$ open set.

Lemma 2.3 [10] Let $(X, \tau)$ be an ITS. If $A$ and $B$ be are two intuitionistic $\alpha$-open sets in $\mathrm{X}$, then $\mathrm{A} \cap \mathrm{B}$ is an intuitionistic $\alpha-$ open set.

Theorem 2.4 [2] Let $(\mathrm{X}, \tau)$ be an ITS and $\left\{\mathrm{A}_{\alpha}: \alpha \in \mathrm{I}\right\}$ be a family of intuitionistic $\beta$-open sets in $X$. Then $\cup_{\alpha \in I} A_{\alpha}$ is also an Intuitionistic $\beta-$ open set.

Lemma 2.4 [1] Let $(X, \tau)$ be an ITS. If $A$ and $B$ be are two intuitionistic $\beta$-open sets in $\mathrm{X}$, then $\mathrm{A} \cap \mathrm{B}$ is not necessarily to be an intuitionistic $\beta$-open set.

Theorem 2.5 [1] In ITS every intuitionistic closed set is intuitionistic $\alpha$-closed set.

Remark 2.1 The converse of the above theorem need not be true we have following example.

Example 2.1 [1] Let $(X, \tau)$ be an ITS where $X=\{a, b, c\}$ and $\tau$ $=\{\Phi \sim, \mathrm{X} \sim,\langle\mathrm{X},\{\mathrm{a}\}, \Phi>,<\mathrm{X}, \Phi,\{\mathrm{b}\}>\}$. Then the intuitionistic set $\mathrm{A}=\langle\mathrm{X}, \Phi,\{\mathrm{a}, \mathrm{c}\}\rangle \subseteq \mathrm{X}$, be an intuitionistic $\alpha$-closed set in $\mathrm{X}$ but not a intuitionistic closed set.

Corollary 2.1 [1] In ITS every intuitionistic $\alpha$-closed set is intuitionistic semiclosed set.

Remark 2.2[1] The converse of the above theorem need not be true we have following example.

Example 2.2 Let $(\mathrm{X}, \tau)$ be an ITS where $\mathrm{X}=\{\mathrm{a}, \mathrm{b}, \mathrm{c}\}$ and $\tau=\{$ $\Phi \sim, \mathrm{X} \sim,<\mathrm{X},\{\mathrm{a}\}, \Phi>,<\mathrm{X}, \Phi,\{\mathrm{b}, \mathrm{c}\}>\}$. Then the intuitionistic set $\mathrm{A}=<\mathrm{X}, \Phi,\{\mathrm{c}\}>\subseteq \mathrm{X}$, be an intuitionistic semiclosed set in $\mathrm{X}$ but not a intuitionistic $\alpha$-closed set.

Corollary 2.2 [1] In ITS every intuitionistic $\alpha$-closed set is intuitionistic preclosed set.

Remark 2.3 [1] The converse of the above theorem need not be true we have following example.

Example 2.3 Let $(\mathrm{X}, \tau)$ be an ITS where $\mathrm{X}=\{\mathrm{a}, \mathrm{b}, \mathrm{c}, \mathrm{d}\}$ and $\tau$ $=\{\Phi \sim, X \sim,<\mathrm{X},\{\mathrm{a}\}, \Phi>,<\mathrm{X},\{\mathrm{c}\}, \varphi>,<\mathrm{X},\{\mathrm{a}, \mathrm{c}\}, \varphi>$, $<\mathrm{X}, \varphi, \varphi>,<\mathrm{X},\{\mathrm{c}\},\{\mathrm{b}\}>,<\mathrm{X}, \varphi,\{\mathrm{b}\}>\}$. Then the intuitionistic set $\mathrm{A}=\langle\mathrm{X},\{\mathrm{c}\},\{\mathrm{a}, \mathrm{b}\}>\subseteq \mathrm{X}$, be an intuitionistic preclosed set in $\mathrm{X}$ but not a intuitionistic $\alpha$ closed set.

Theorem 2.6 [1] In ITS every intuitionistic semiclosed set is intuitionistic $\beta$-closed set.

Remark 2.4 [1] The converse of the above theorem need not be true we have following example.

Example 2.4 Let $(\mathrm{X}, \tau)$ be an ITS where $\mathrm{X}=\{\mathrm{a}, \mathrm{b}, \mathrm{c}, \mathrm{d}\}$ and $\tau$ $=\{\Phi \sim, X \sim,<\mathrm{X},\{\mathrm{a}\}, \Phi>,<\mathrm{X},\{\mathrm{c}\}, \varphi>,<\mathrm{X},\{\mathrm{a}, \mathrm{c}\}, \varphi>$, $<\mathrm{X}, \varphi, \varphi>,<\mathrm{X},\{\mathrm{c}\},\{\mathrm{b}\}>,<\mathrm{X}, \varphi,\{\mathrm{b}\}>\}$. Then the intuitionistic set $\mathrm{A}=\langle\mathrm{X},\{\mathrm{c}\},\{\mathrm{a}, \mathrm{b}\}\rangle \subseteq \mathrm{X}$, be an intuitionistic $\beta$-closed set in $\mathrm{X}$ but not a intuitionistic semiclosed set. 
Theorem 2.7 [1] In ITS every intuitionistic preclosed is intuitionistic $\beta$-closed set.

Remark 2.5 [1] The converse of the above theorem need not be true we have following example.

Example 2.5 Let $(X, \tau)$ be an ITS where $X=\{a, b\}$ and $\tau=$ $\{\Phi \sim, X \sim,<\mathrm{X}, \Phi,\{\mathrm{a}\}>,<\mathrm{X},\{\mathrm{b}\}, \Phi>\}$. Then the intuitionistic set $\mathrm{A}=\langle\mathrm{X}, \Phi,\{\mathrm{a}\}>\mathrm{X}$, be an intuitionistic $\beta$-closed set in $X$ but not intuitionistic preclosed set.

Theorem 2.8 [1] In ITS every intuitionistic $\alpha$-closed set is intuitionistic $\beta$-closed set.

Remark 2.6 [1] The converse of the above theorem need not be true we have following example.

Example 2.6 Let $(\mathrm{X}, \tau)$ be an ITS where $\mathrm{X}=\{\mathrm{a}, \mathrm{b}\}$ and $\tau=$ $\{\Phi \sim, X \sim,<\mathrm{X}, \Phi,\{\mathrm{a}\}>,<\mathrm{X},\{\mathrm{b}\}, \Phi>\}$. Then the intuitionistic set $\mathrm{A}=<\mathrm{X}, \Phi,\{\mathrm{a}\}>\subseteq \mathrm{X}$, be an intuitionistic $\beta$-closed set in $X$ but not a intuitionistic $\alpha$-closed set.

\section{INTUITIONISTIC sgp-CLOSED SET}

Definition 3.1 Let $(\mathrm{X}, \tau)$ be an ITS and A be an intuitionistic set is said to be intuitionistic sgp-closed (for short Isgpclosed) set if $\operatorname{Ipcl}(\mathrm{A}) \subseteq \mathrm{U}$ whenever $\mathrm{A} \subseteq \mathrm{U}$ and $\mathrm{U}$ is intuitionistic semiopen set in $\mathrm{X}$.

We note that the concept of intuitionistic sgp-closed is a generalized form of intuitionistic closed set. We have following results

Theorem 3.1 In ITS every intuitionistic closed set is intuitionistic sgp-closed set.

Proof Let $(X, \tau)$ be an ITS and A be an intuitionistic closed set. Let $\mathrm{A} \subseteq \mathrm{V}$ and $\mathrm{V}$ is an intuitionistic semiopen set in $\mathrm{X}$. Since $A$ be an intuitionistic closed set this implies that $\operatorname{Icl}(\mathrm{A})=\mathrm{A}$. Thus we have $\operatorname{Icl}(\mathrm{A}) \subseteq \mathrm{V}$. Since $\operatorname{Ipcl}(\mathrm{A}) \subseteq$ $\operatorname{Icl}(\mathrm{A})$, therefore $\operatorname{Ipcl}(\mathrm{A}) \subseteq \mathrm{V}$ whenever $\mathrm{A} \subseteq \mathrm{V}$ and $\mathrm{V}$ is intuitionistic semiopen set in $\mathrm{X}$. Hence $\mathrm{A}$ be an intuitionistic sgp-closed set.

Remark 3.1 the converse of the above theorem need not be true we have following example.

Example 3.1 Let $(X, \tau)$ be an ITS where $X=\{a, b, c\}$ and $\tau=\{$ $\Phi \sim, \mathrm{X} \sim,<\mathrm{X}, \Phi,\{\mathrm{a}\}>,<\mathrm{X},\{\mathrm{b}, \mathrm{c}\}, \Phi>\}$. Then the intuitionistic set $\mathrm{A}=<\mathrm{X},\{\mathrm{b}\},\{\mathrm{c}\}>\subseteq \mathrm{V}$ where $\mathrm{V}=<\mathrm{X},\{\mathrm{b}$, c\}, $\Phi>$ be an intuitionistic semi open set in $X$. Thus we have $\mathrm{A}$ is an intuitionistic sgp-closed set but not intuitionistic closed set.
Definition 3.2 Let $(X, \tau)$ be an ITS and A be an intuitionistic set in $X$. Then $A$ is said to be intuitionistic sgp-open set if its compliment is intuitionistic sgp closed set.

Remark 3.2 From the above definition we note that in a intuitionistic topological space, each intuitionistic open set is intuitionistic sgp-open set. However the converse may not true.

Remark 3.3 In ITS the intersection of two intuitionistic sgpclosed sets need not be necessarily to sgp-closed set. We have following example.

Example 3.2 Let $(X, \tau)$ be an ITS where $X=\{a, b, c\}$ and $\tau=$ $\{\Phi \sim, \mathrm{X} \sim,<\mathrm{X},\{\mathrm{a}\}, \Phi>,<\mathrm{X}, \Phi,\{\mathrm{b}\}>\}$. Then the intuitionistic set $\mathrm{A}=<\mathrm{X},\{\mathrm{a}, \mathrm{c}\}, \Phi>$ and $\mathrm{B}=<\mathrm{X},\{\mathrm{b}, \mathrm{c}\}$, $\Phi>$ are two intuitionistic sgp-closed sets but $A \cap B=<X$, $\{c\}, \Phi>$ is not intuitionistic sgp-closed set.

Theorem 3.2 In ITS every intuitionistic preclosed set is intuitionistic sgp-closed set.

Proof Let $(X, \tau)$ be an ITS and A be an intuitionistic set. Let $\mathrm{A} \subseteq \mathrm{V}$ and $\mathrm{V}$ is an intuitionistic semiopen set in $\mathrm{X}$. Since $\mathrm{A}$ be an intuitionistic preclosed set this implies that $\operatorname{Ipcl}(\mathrm{A})=$ A. Thus we have $\operatorname{Ipcl}(\mathrm{A}) \subseteq \mathrm{V}$ whenever $\mathrm{A} \subseteq \mathrm{V}$ and $\mathrm{V}$ is intuitionistic semiopen set in $\mathrm{X}$. Hence $\mathrm{A}$ be an intuitionistic sgp-closed set.

Remark 3.4 the converse of the above theorem need not be true we have following example.

Example 3.3 Let $(X, \tau)$ be an ITS where $X=\{a, b, c\}$ and $\tau=$ $\{\Phi \sim, \mathrm{X} \sim,<\mathrm{X}, \Phi,\{\mathrm{a}\}>,<\mathrm{X},\{\mathrm{b}, \mathrm{c}\}, \Phi>\}$. Then the intuitionistic set $\mathrm{A}=<\mathrm{X},\{\mathrm{c}\}, \Phi>\subseteq \mathrm{V}$ where $\mathrm{V}=\mathrm{X} \sim$ be an intuitionistic semi open set in $X$. Thus we have $A$ is an intuitionistic sgp-closed set but not intuitionistic preclosed set.

Corollary 3.1 In ITS every intuitionistic $\alpha$-closed set is intuitionistic sgp-closed set.

Proposition 3.1 In ITS there is no relation between intuitionistic semi-closed and intuitionistic sgp-closed set. We have given following example.

Example 3.4 Let $(X, \tau)$ be an ITS where $X=\{a, b, c\}$ and $\tau=$ $\{\Phi \sim, \mathrm{X} \sim,<\mathrm{X},\{\mathrm{a}\}, \Phi>,<\mathrm{X}, \Phi,\{\mathrm{b}, \mathrm{c}\}>\}$. Then the intuitionistic set $\mathrm{A}=<\mathrm{X}, \Phi,\{\mathrm{c}\}>\subseteq \mathrm{V}$ where $\mathrm{V}=<\mathrm{X},\{\mathrm{a}\}$, $\Phi>$ be an intuitionistic open set in X. Thus we have A is an intuitionistic semi-closed set but not an intuitionistic sgp closed set.

Example 3.5 Let $(X, \tau)$ be an ITS where $X=\{a, b, c\}$ and $\tau=$ $\{\Phi \sim, \mathrm{X} \sim,<\mathrm{X}, \Phi,\{\mathrm{a}\}>,<\mathrm{X},\{\mathrm{b}, \mathrm{c}\}, \Phi>\}$. Then the 
intuitionistic set $\mathrm{A}=\langle\mathrm{X},\{\mathrm{b}\},\{\mathrm{c}\}>\subseteq \mathrm{V}$ where $\mathrm{V}=\langle\mathrm{X},\{\mathrm{b}$, c), $\Phi>$ be an intuitionistic semiopen set in $\mathrm{X}$. Thus we have $\mathrm{A}$ is an intuitionistic sgp-closed set but not intuitionistic semiclosed set.

Proposition 3.2 In ITS there is no relation between intuitionistic $\beta$-closed and intuitionistic sgp-closed set. We have given following example.

Example 3.6 Let $(X, \tau)$ be an ITS where $X=\{a, b, c\}$ and $\tau=\{$ $\Phi \sim, \mathrm{X} \sim,<\mathrm{X},\{\mathrm{a}\}, \Phi>,<\mathrm{X}, \Phi,\{\mathrm{b}, \mathrm{c}\}>\}$. Then the intuitionistic set $\mathrm{A}=<\mathrm{X}, \Phi,\{\mathrm{c}\}>\subseteq \mathrm{V}$ where $\mathrm{V}=<\mathrm{X},\{\mathrm{a}\}$, $\Phi>$ be an intuitionistic open set in X. Thus we have A is an intuitionistic $\beta$-closed set but not a intuitionistic sgp closed set.

Example 3.7 Let $(X, \tau)$ be an ITS where $X=\{a, b, c\}$ and $\tau=\{$ $\Phi \sim, \mathrm{X} \sim,<\mathrm{X},\{\mathrm{a}\}, \Phi>,<\mathrm{X},\{\mathrm{b}, \mathrm{c}\}, \Phi>\}$. Then the intuitionistic set $\mathrm{A}=<\mathrm{X},\{\mathrm{c}\}, \Phi>\subseteq \mathrm{V}$ where $\mathrm{V}=<\mathrm{X},\{\mathrm{b}$, c $\}, \Phi>$ be an intuitionistic open set in X. Thus we have A is an intuitionistic sgp-closed set but not a intuitionistic $\beta$ closed set.

Remark 3.5 From the above discussion and known results we have the following diagram of implications:

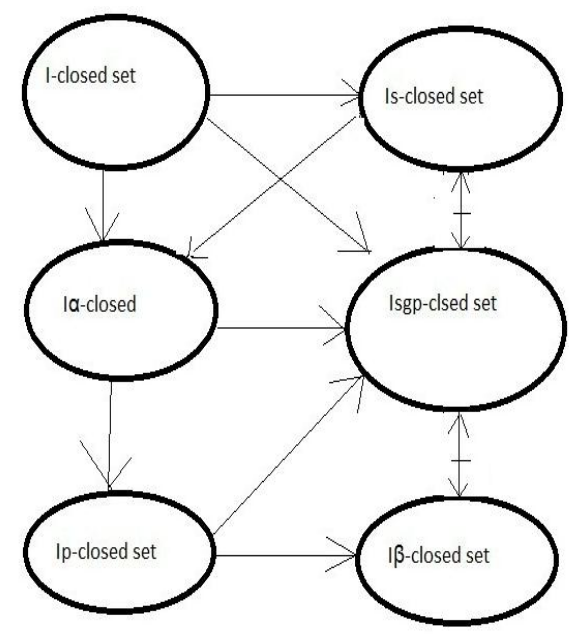

Figure 3.1 Relations between Intuitionistic closed sets and Intuitionistic sgp-closed set.

In this diagram A $\longrightarrow$ B" we mean A implies B but not conversely and "A $\quad B$ " means A and B independent of each other

Theorem 3.3 Let $(X, \tau)$ be an ITS and if $\mathrm{A}$ be an intuitionistic sgp-closed set and $\mathrm{A} \subseteq \mathrm{B} \subseteq \operatorname{Ipcl}(\mathrm{A})$ then $\mathrm{B}$ be an intuitionistic sgp-closed set.

Proof Let $(\mathrm{X}, \tau)$ be an ITS and let $\mathrm{U}$ be an intuitionistic semi open set s.t $\mathrm{B} \subseteq \mathrm{U}$. Since $\mathrm{A} \subseteq \mathrm{B}$ then $\mathrm{A} \subseteq \mathrm{U}$ if $\mathrm{A}$ be an intuitionistic sgp-closed set then $\operatorname{Ipcl}(\mathrm{A}) \subseteq \mathrm{U}$. Now since B $\subseteq \operatorname{Ipcl}(\mathrm{A})$ this implies that $\operatorname{Ipcl}(\mathrm{B}) \subseteq \operatorname{Ipcl}(\mathrm{A}) \subseteq \mathrm{U}$. Thus we have $B$ be an intuitionistic sgp-closed set.

Theorem 3.4 Let $(\mathrm{X}, \tau)$ be an ITS and if $\mathrm{A}$ be an intuitionistic sgp-open set and $\operatorname{IPint}(\mathrm{A}) \subseteq \mathrm{B} \subseteq \mathrm{A}$ then $\mathrm{B}$ be an intuitionistic sgp-open set.

Proof Let $(\mathrm{X}, \tau)$ be an ITS and let A be an intuitionistic sgpopen set and $\operatorname{Ipint}(\mathrm{A}) \subseteq \mathrm{B} \subseteq \mathrm{A}$ this implies that $\mathrm{A}^{\mathrm{c}} \subseteq \mathrm{B}^{\mathrm{c}} \subseteq$ $(\operatorname{Ipint}(\mathrm{A}))^{\mathrm{c}}, \mathrm{A}^{\mathrm{c}} \subseteq \mathrm{B}^{\mathrm{c}} \subseteq \operatorname{Ipint}(\mathrm{A})^{\mathrm{c}}$ and $\mathrm{A}^{\mathrm{c}}$ is intuitionistic sgpclosed set. Thus by Theorem, $\mathrm{B}^{\mathrm{C}}$ be an intuitionistic sgpclosed set and $\mathrm{B}$ be an intuitionistic sgp-open set.

\section{CONCLUSION}

We conclude that the concept of intuitionistic sgp-closed set is a generalization of intuitionistic preclosed set. Also further we conclude that the concept of intuitionistic sgpclosed set and intuitionistic semiclosed set, intuitionistic sgp-closed set and intuitionistic $\beta$-closed set are independent of each other.

\section{ACKNOWLEDGEMENT}

We would like to thank my guide and referee for his/her comments and suggestions on the manuscript.

\section{REFERENCES}

[1] A. Singaravelan, "On intuitionistic $\beta$-open sets",Mathematical science I. J., Vol. 5, 2016.

[2] A. Singaravelan and G. Ilango, " Some more properties Of intuitionistic $\beta$-open sets", Int. Jour. Of pure and Applied Mathematics, vol. 106, no 8, 13-20, 2016.

[3] D. Coker, "An introduction to intuitionistic topological Spaces", Preliminary report, Akdeniz university, Math. Dept. Turkey, 5156, 1995.

[4] D. Coker, "A note on intuitionistic sets and intuitionistic Points",Turkish J. Math., 20, No. 3, 343-351, 1996.

[5] D. Coker, An Introduction to intuitionistic topological spaces, BUSEFAL, 81, 51-56, 2000. [6] G. Ilango and S. Selvanyaki, "Generalized pre regular closed sets in intuitionistic topological spaces”, IJMA, 5(4), 30-36, 2014.

[7] G. Navalagi and M. Bhat, "On sgp-closed sets in Topological spaces", Jour. Of Applied Mathematical Analysis and Applications, 3(1), 45- 58, 2007.

[8] G. Sasikala and M.N. Krishnan, "Study on Intuitionistic Semiopen Sets", IOSR journal of Mathematics, vol. 12, Isssue 6 Ver. III, 2016, 79- 84.

[9] G. Sasikala and M.N. Krishnan, "On intuitionistic preiopen Sets", Inter. journal of Pure and Applied Mathematics, vol. 116, no 24, 281-292, 2017.

[10] G. Sasikala and M.N. Krishnan, "Study on intuitionistic $\alpha$-open sets and $\alpha$-closed sets", Int. Jour. of Mathematics Archive, 8(1), 26-30, 2017.

[11] J.P. Bajpai and S.S. Thakur, "Intuitionistic fuzzy sgp-closed sets", Int. Jour. Of Latest Trends in Engineering and Technology", Vol 
8, Issue 1, 636-642, 2017.

[12] J.T., Yaseen S. and Abdualbaqi L., "Some generalized sets and generalized mapping in intuitionistic topological spaces", J. of alQadisiyah for computer science and mathematics, 7, 2, 2015.

[13] Y.J. Yaseen and A.G. Raouf, "On generalized closed sets and generalized continuity on intuitionistic topological spaces", J. of al-anbar uni. for pure science, 3,1, 2009.

\section{AUTHORS PROFILE}

Poonam Agrawal received the B.Sc and M.Sc degrees in mathematics from A.P.S. University Rewa (M.P.) in 2006 and 2008 respectively. After that she has been teaching since 2009 to till date in various college. Now she is pursuing Ph.D. in RDVV Jabalpur.

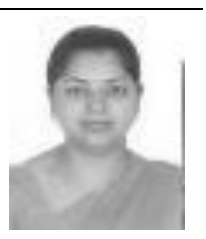

Dr. J.K. Maitra pursed his M.Sc., M.Phil., and Ph.D. in Mathematics from R.D. University, Jabalpur in 1991, 1994 and 1998. He is currently working as Associate Professor in Department of Mathematics and Computer Science, from R.D. University, Jabalpur since 1998. He is Life

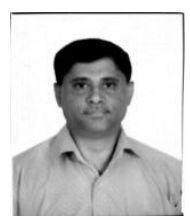
member of Indian Mathematical Society. He has published more than 25 research papers in reputed international and national journals and participated in several conferences including ICM. His main research work focuses on Topology, Fuzzy Topology and Algebraic Topology. He has 20 years of teaching experience and 25 years of research experience. 